\title{
Os programas de recuperação paralela e a qualidade da educação em São Paulo
}

\author{
Programs of parallel studies and the \\ quality of education in São Paulo
}

\author{
Josilda Maria BELTHER ${ }^{1}$
}

RESUMO: Com a adoção do regime de ciclos e da progressão continuada pela rede pública estadual paulista, em 1997, a reprovação foi abolida para garantir maior permanência dos alunos na escola. Sem a reprovação, os programas de recuperação paralela da aprendizagem foram elevados a elemento essencial para a garantia da qualidade do ensino e para evitar a promoção automática. Partindo dessa importância atribuída aos programas de recuperação paralela dos alunos, buscamos, no presente texto, analisar a estrutura e o funcionamento desses programas, bem como investigar as suas contribuições para a qualidade do ensino paulista. Para desenvolver essa pesquisa, foram utilizados os pressupostos teóricos da pedagogia crítico-social dos conteúdos e coleta de dados por meio de entrevistas com professores coordenadores pedagógicos, entrevista coletiva com professores das classes de recuperação paralela e observações em salas de aulas de 17 escolas estaduais. A análise realizada revelou-nos as principais dificuldades enfrentadas pela escola organizada em ciclos e sem reprovação.

Palavras-chave: recuperação, reforço, qualidade, ciclos, aprovação automática

ABSTRACT: Having adopted a system of cycles and students' on-going progress in São Paulo state schools, in 1997, failing was abolished to guarantee that students would remain longer in schools. Without having to fail students, programs of parallel studies were considered an essential element to guarantee quality in teaching and to avoid automatic passing. As a starting point, taking into account the importance of these programs of parallel studies for students, we intend to analyze how they are structured and how they work as well as look into how these programs can contribute towards the quality of teaching in the state of São Paulo. For this research, theoretical presuppositions of critical-social pedagogy for the content were used. Data was collected through interviews with pedagogical teacher-coordinators, collective interviews with teachers of parallel studies while also having class observation in 17 state schools. This analysis

\footnotetext{
${ }^{1}$ Mestre em Educação Escolar pela Universidade Estadual Paulista Júlio de Mesquita Filho. Professora da UNESP. E mail: jmbelther@uol.com.br
}

Olhar de professor, Ponta Grossa, 8(2): 163-177, 2005. 
showed the main difficulties faced by the schools using the cycle system and adopting the 'no-failing' method.

Key words: parallel studies, extra studies, quality, cycles, automatic pass

\section{INTRODUÇÃO}

A rede pública estadual paulista adotou o regime de progressão continuada dos alunos do ensino fundamental em 1998, por meio da Deliberação 09/97 e Resolução 08/97. Por essa legislação, a escola deixou a secular organização seriada no currículo escolar, adotou o regime de ciclos e aboliu a reprovação dos alunos.

Os ciclos exigem escola pautada em novos paradigmas de avaliação, aprendizagem, currículo, papel da escola e relação professor-aluno. As mudanças deverão ocorrer tanto no que diz respeito à prática dos professores em sala de aula, quanto no que diz respeito ao funcionamento de cada escola e também do sistema escolar.

Sem essas mudanças a escola está sujeita a adotar mera aprovação automática, sem cuidar da garantia da aprendizagem por parte dos alunos. Outra condição para a garantia dessa aprendizagem é a recuperação paralela ou reforço da aprendizagem dos alunos, pois em sistemas em que os professores ainda não estão tão preparados e adaptados com classes heterogêneas e compostas por um número de alunos que não permite um trabalho individualizado, as aulas de reforço constituem mecanismo essencial para garantir que, ao final do ciclo, todos os alunos indistintamente alcancem níveis próximos de conhecimentos e competências.

Neste trabalho, após análise da legislação e dos pressupostos teóricos dos ciclos e da progressão continuada, procedeu-se à elaboração de uma pesquisa empírica em 17 escolas de uma diretoria de ensino do interior paulista, por meio de entrevistas com professores coordenadores pedagógicos e professores das classes de reforço. Os resultados mostram a estrutura e o funcionamento dos programas de recuperação paralela e possibilitam reflexões sobre algumas medidas que são necessárias para a efetivação de uma escola organizada em ciclos e com qualidade de ensino.

\section{OS CICLOS: NOVOS PARADIG- MAS EANTIGAS RESISTÊNCIAS}

Os ciclos constituem uma forma de estruturar o currículo escolar que é diversa da organização em séries, pois compreendem períodos com maior duração. Se a série corresponde a um período de um ano, os ciclos em geral correspondem a períodos de 2 , 3 ou 4 anos. No Estado de São Paulo, 
o ensino fundamental ficou estruturado em dois ciclos: ciclo I, de $1^{\mathrm{a}}$ a $4^{\mathrm{a}}$ séries; e ciclo II, de $5^{\mathrm{a}}$ a $8^{\mathrm{a}}$ séries. Sem a antiga fragmentação em séries, a escola pode atender mais facilmente a alunos em estágios de desenvolvimento diferenciados e com ritmos de aprendizagem diversos.

Esse espaço de tempo maior que o ciclo oferece para o desenvolvimento de habilidades e conteúdos com os alunos, possibilita à escola trabalhar de forma singular e de acordo com as exigências de sua realidade, de seu alunado. Adotar os ciclos supõe respeitar os diferentes ritmos dos alunos, supõe aceitar que diferentes alunos com diferentes experiências extra-escolares e acadêmicas podem aprender os mesmos conteúdos em prazos e momentos diferenciados, uma vez que seus ritmos não são lineares nem homogêneos, embora apresentem uma progressão contínua.

O referido sistema permite que alunos com maiores dificuldades ou que apresentam ritmo mais lento para aprender possam prosseguir com seu grupo de idade, condição essencial para a construção de sua identidade e auto-estima (Silva, 2001).

A organização do ensino em ciclos também atende a propósitos democratizantes e de inclusão social, pois regulariza o fluxo de alunos ao longo da escolarização, na medida que elimina ou limita a repetência apenas ao último ano do ciclo. Sem a repetência, o sistema escolar deixa de ser seletivo e excludente, mostran- do-se mais inclusivo, democrático e a serviço do aluno.

Como a evasão sempre foi a maior aliada da reprovação, os ciclos também asseguram, com a regularização do fluxo, o princípio de permanência do aluno na escola, objetivo esse buscado desde o século passado, após as políticas de expansão quantitativa da rede escolar.

Assim, os ciclos constituem uma proposta político-pedagógica, visto que nela reside o pressuposto de um processo ensino-aprendizagem contínuo e um repensar constante desse processo por parte do professor. Esse repensar é imprescindível ao trabalho do professor, já que possibilita a tomada de decisões e a adoção de medidas necessárias ao desenvolvimento do aluno ainda durante o processo de ensino.

A organização do ensino em ciclos não é novidade. Os ciclos foram discutidos e defendidos desde a década de 50 no Brasil e adotados em vários estados brasileiros a partir da década de 70 do século passado. $\mathrm{Na}$ década de 80, alguns estados brasileiros como Paraná, Minas Gerais e São Paulo adotaram os ciclos de alfabetização com propósitos políticos e educacionais. Eles adotaram um modelo de aprovação automática na passagem da $1^{\mathrm{a}}$ para a $2^{\mathrm{a}}$ séries e, ao mesmo tempo, pretendeu-se atender a um maior contingente da população e assegurar a progressão contínua dos alunos por meio de um tratamento mais adequado a cada criança, de acordo 
com seu nível de conhecimento, pondo-se fim à exclusão social e cultural dos alunos.

Também não se desconhece que outros países como Inglaterra e Estados Unidos adotaram o regime de ciclos escolares por meio do sistema de avanços progressivos nos quais a idade era o critério determinante para a formação dos grupos ou classes escolares. Segundo Barreto e Mitrulis (2002), embora esses países apresentem no seu bojo uma proposta mais democrática de educação do que os sistemas que instituem a repetência, acabam por proceder a uma seleção social, na medida em que permitem o alcance de diferentes níveis de aprendizagem, conhecimentos e competências por alunos da mesma idade e com o mesmo tempo de permanência na escola.

No Brasil, o que se pretende é que todos os alunos indistintamente alcancem um mesmo nível de conhecimentos ao final dos ciclos e é por isso que a legislação autoriza a permanência do aluno no mesmo ciclo, em casos em que ele ainda não domina os conteúdos e habilidades do ciclo.

Dessa forma, a escola precisa garantir que até a conclusão do ciclo o aluno efetivamente aprenda um conjunto de conhecimentos e adquira um leque de competências necessários à sua inserção social. Durante o ciclo, algumas medidas ou providências devem ser tomadas no percurso do processo de ensino-aprendizagem, tais como a recuperação contínua, a ser desenvolvida pelo professor regular da classe, e as aulas de recuperação paralela e reforço, a serem desenvolvidas em período contrário ao horário das aulas. Essas medidas são essenciais para a garantia da qualidade de ensino, pois são elas que permitem o avanço com aprendizagem.

Para o professor, especialmente para os professores do segundo ciclo do ensino fundamental, o regime de progressão continuada constitui uma inovação e um desafio, uma vez que a escola, desde o período medieval, estrutura o currículo de forma seriada, com conteúdos determinados para cada série e para cada disciplina. Logo, trabalhar interdisciplinarmente e avaliar de forma contínua é tarefa árdua e nova.

Já os professores do primeiro ciclo do ensino fundamental paulista são menos resistentes à progressão continuada porque são polivalentes, conseguem avaliar e analisar o desempenho do aluno integralmente e não em disciplinas estanques, como se verifica entre os professores especialistas do ciclo II. Além do mais, as experiências com o Ciclo Básico já permitiram uma reflexão sobre a temática. Também não se desconhece que os professores primários também foram muito resistentes ao projeto do Ciclo Básico, como também foram resistentes os professores da rede pública paulista na década de 60 , com relação ao Ato 306/68.

De acordo com Barreto (2002, p. 42): 
Os professores reclamam constantemente que não estão preparados para trabalhar com os ciclos. Efetivamente, nem a Universidade e nem Supervisão estão preparadas para trabalhar com os ciclos porque eles, nas dimensões em que estão propostos, são uma proposta nova no horizonte das políticas educacionais contemporâneas.

A resistência apresentada pelos professores ao regime de ciclos e à não reprovação dos alunos foi objeto de vários estudos acadêmicos, dentre os quais destacamos os trabalhos de Silva (2001), Paro (2001) e Guilherme (2001). Vários motivos justificam a insatisfação e resistência que os professores têm com relação à não reprovação. Entre eles, os professores reclamam da perda da autoridade em sala de aula devido à não reprovação, o que gera indisciplina em sala de aula. Como se sabe, o professor sempre utilizou as notas e provas como meio de garantir a disciplina e como forma de assegurar que o aluno estudasse; sem a reprovação, os professores queixam-se da incapacidade que enfrentam em motivar os alunos para os estudos. Eles perderam o poder de levar os alunos a estudarem.

Os docentes também indicam a falta de democratização do saber: segundo eles, sem reprovação a escola pública não valoriza os conteúdos e, portanto, oferece uma escola pobre para os pobres. A idéia de que a pro- gressão continuada não valoriza a assimilação dos conhecimentos é corrente entre os professores e denota uma falta da real compreensão dos propósitos dessa proposta. Paro (2001) considera que, às vezes, os professores lamentam mais pelo fato de os alunos passarem de ano sem saber, do que propriamente por eles não saberem.

Outro argumento que sustenta a resistência dos professores ao regime de progressão continuada diz respeito à idéia de que a reprovação serve como motivação para o aluno aprender. Há um entendimento de que a falta de reprovação é que gera o não estudar e não aprender, assim como de que a prova é instrumento de aprendizagem e não um instrumento para nortear o trabalho do professor. Ela também não é vista como instrumento de luta contra as desigualdades e fracasso dos alunos.

Somados a esses, ainda aparecem mais dois argumentos: o de que a progressão continuada não torna o aluno responsável e não prepara para a vida, pois "a vida lá fora reprova" o fato denota que, da forma como está estruturada, a escola não educa e nem prepara para a vida; o outro argumento é o de que a progressão continuada foi instituída apenas para reduzir os elevados índices ou estatísticas de reprovação.

Por outro lado, faz-se necessário analisar os aspectos institucionais a que estão submetidos os professores e analisar o discurso que o poder 
público elabora. Muito comumente o Estado culpabiliza o professor pelos problemas da escola e pelo insucesso dos alunos, em uma postura muitas vezes de ocultar a sua própria negligência. Segundo Paro (2001), sem as condições necessárias ao trabalho docente (número adequado de alunos por sala, salários condizentes para evitar sobrejornada dos professores, formação continuada etc), muitas vezes os professores acabam impossibilitados de realizar um trabalho a contento e apelam para a reprovação como salvação que os livre do vexame de serem tratados de incompetentes (2001, p.99).

Juntamente com os ciclos, o regime de progressão continuada adotou um novo conceito de avaliação. Esta agora deve ser contínua e cumulativa do desempenho dos alunos, deve ter uma função diagnóstica, investigativa que indica intervenções para o acompanhamento contínuo do avanço do aluno. A avaliação serve para ajudar o aluno a aprender, na medida em que indica conquistas e dificuldades que possibilitam ao professor reordenar sua ação pedagógica.

Esse modelo de avaliação supõe constantes avaliações por parte do professor, para identificar as dificuldades dos alunos e enviar os alunos para as aulas de recuperação paralela e reforço. Isso exige uma nova concepção de ensino e aprendizagem, bem como um novo modelo de professor.
Quanto ao processo ensinoaprendizagem, é preciso crer que todo aluno é capaz de aprender e, portanto, o professor deve estar atento à diversidade presente na sala de aula e às individualidades dos alunos, para respeitar os seus diferentes ritmos e estilos de aprendizagem.

Tal atenção implica habilidade por parte do professor para lidar com a heterogeneidade presente em cada sala de aula e intervir sempre que necessário, durante o processo e não apenas no final do ano letivo, a fim de assegurar o avanço de todos os alunos, sem distinção. O avanço supõe um aluno motivado, o que se consegue com as situações de aprendizagem significativas e contextualizadas oferecidas pelo professor. Nesse contexto, a relação professor/aluno deve ser de apoio e parceria, e não ameaçadora.

Além da avaliação contínua e cumulativa dos alunos pelo professor da classe regular, a legislação determinou a realização de recuperação paralela e contínua dos alunos com menor rendimento escolar. Por isso, a escola deve contemplar em seu projeto pedagógico formas e instrumentos de recuperação contínua e paralela para esses alunos. Juntamente com esse modelo de avaliação, nos primeiros anos da implantação da progressão continuada dos alunos a Secretaria Estadual de Educação adotou a proposta de Estudos de Recuperação e Avaliação nas Férias.

Essa proposta constituiu-se em 
modalidade de recuperação intensiva para os alunos que não conseguissem desempenho suficiente ou satisfatório durante o ano letivo. Foi aplicada nas férias de janeiro de 1998 , 1999 e 2000 e deveria durar no mínimo 20 dias. Nesse modelo de recuperação intensiva não havia o propósito de desenvolver em alguns dias os conteúdos não dominados durante o ano letivo. Segundo o documento que a instituiu, o objetivo era o desenvolvimento de conceitos e habilidades básicas necessárias em cada componente curricular, para a continuidade dos estudos.

A proposta de recuperação intensiva nas férias foi amplamente combatida pelos professores e vista com ironia pelos alunos, que a entendiam como condição para "passar de ano". Foi extinta em 2003, pela Resolução SE 84, de 15/08/2003. Abolida a reprovação, abolida a recuperação intensiva, as aulas de recuperação paralela e reforço restaram como alternativa importante para não transformar a progressão continuada dos alunos em promoção automática sem aprendizagem.

De fato, se não há reprovação nem recuperação nas férias e, além disso, o número de alunos por classe não é adequado para um trabalho individualizado e garantidor da atenção de que os alunos necessitam, as aulas de reforço configuram-se como alternativa importante para o avanço do aluno com efetiva aprendizagem.

\section{ALEGISLAÇÃO REGULAMENTA- DORA DO REFORÇO E RECUPE- RAÇÃO PARALELADOSALUNOS}

A temática da recuperação paralela e reforço dos alunos está contemplada na Lei de Diretrizes e Bases da Educação Nacional - Lei 9394/96, na Deliberação 07/97 e Indicação CEE 08/97, que instituíram a progressão continuada dos alunos, e ainda no Regimento Comum das Escolas Estaduais.

Em seu artigo 24, a Lei de Diretrizes e Bases da Educação Nacional determina que a verificação do rendimento escolar deve observar o critério da avaliação contínua e da obrigatoriedade de estudos de recuperação, de preferência paralelos ao período letivo, para os casos de baixo rendimento escolar.

A Deliberação 09/97, do Conselho Estadual de São Paulo, determina em seu artigo $1^{\circ}$ que a avaliação do processo ensino-aprendizagem deve contemplar recuperação contínua e paralela, e recuperação ao final de cada período letivo; o artigo $3^{\circ}$ determina que o projeto educacional de implantação da progressão continuada deve especificar mecanismos que assegurem atividades de reforço e recuperação paralela contínuas, ao longo do processo.

As Indicações 8/97 e 22/97, do Conselho Estadual de São Paulo, alertam para a importância da recuperação paralela e reforço como instrumentos essenciais para a garantia da

Olhar de professor, Ponta Grossa, 8(2): 163-177, $2005 . \overline{169}$ 
aprendizagem progressiva, quando a avaliação indicar a sua necessidade.

As Normas Regimentais Básicas para as escolas estaduais elaboradas em 1998, que garantiram a implementação da progressão continuada, estabelecem as funções da avaliação do processo de ensino e da aprendizagem. Entre elas, destaca-se a de fundamentar as decisões do conselho de classe quanto à necessidade de procedimentos paralelos ou intensivos de reforço e recuperação da aprendizagem e à obrigatoriedade de realização de atividades de recuperação e reforço para todos os alunos, nas disciplinas em que o aproveitamento for considerado insatisfatório.

A legislação posterior que regulamentou os estudos de recuperação e reforço dos alunos em nível estadual consistiu de diversas resoluções elaboradas pela Secretaria Estadual de Educação de São Paulo, uma ampliando a outra e adequando-se aos problemas encontrados pela realidade educacional.

A primeira legislação a regulamentar os referidos estudos e reforço foi a Resolução 46/96, quando o professor do reforço ainda era o mesmo da classe regular. Essa resolução determinava uma carga horária de, no mínimo, 3 horas semanais, fora do horário regular das aulas. Essa carga horária semanal manteve-se até a Resolução 27/2002, quando foi ampliado o número de aulas para até 5 aulas semanais.
Em 1999 a Resolução SE 7/99 inova, ao determinar os períodos em que deveriam ocorrer as ações de recuperação paralela e reforço dos alunos: maio, junho, setembro, outubro e novembro. Antes dessa resolução a escola poderia organizar a recuperação paralela dos alunos de acordo com o projeto pedagógico da escola e os seus projetos de recuperação e reforço. Atualmente, com a Resolução SE 42/2004, esse período foi ampliado: no primeiro semestre, ele acontece a partir da primeira quinzena de março até o final de junho; e no segundo semestre, a partir da segunda quinzena de agosto até o final da primeira quinzena de dezembro. $\mathrm{O}$ cumprimento, ou não, pela escola do início e término das aulas no referido período fica sob a responsabilidade da supervisão de ensino, atividade extremamente importante para a garantia de uma escola com qualidade de ensino.

A Resolução SE 67/98 manteve as diretrizes anteriores e inovou ao prever a admissão ou contratação de professores exclusivamente para as aulas de reforço. Assim, se até então eram os professores das classes regulares que deveriam ministrar as aulas de reforço, com essa resolução a escola poderia contratar um novo professor para trabalhar com os alunos com dificuldades não superadas em classe.

A idéia de outro professor para as aulas de reforço foi inovadora com relação ao sistema do Ciclo Básico 
adotado em São Paulo, em que o professor tinha uma jornada única e era também responsável pelas aulas de recuperação de seus alunos, em período contrário ao seu horário de aulas, momento em que completava sua jornada de trabalho. Com um novo professor para o aluno, torna-se indispensável assegurar a comunicação entre os dois docentes para garantir um vínculo de compromisso com a aprendizagem do aluno. Esse vínculo pode ocorrer durante os HTPCs e reuniões de Conselho de Classe/Série, momentos esses em que a presença do professor do reforço é indispensável.

A Resolução SE 40/2001, que dispõe sobre a atribuição de aulas de reforço e recuperação, determina que os professores responsáveis pelas aulas de reforço deverão ser escolhidos prioritariamente entre os docentes em exercício na unidade escolar. Depois dessa escolha, as aulas serão atribuídas aos candidatos selecionados pela Diretoria de Ensino. Além disso, cabe ao Diretor da Escola selecionar os professores primeiramente a partir do critério do comprometimento com o desenvolvimento da proposta de reforço dos alunos, independentemente do seu vínculo funcional e classificação.

Essa determinação atribui ao Diretor da Escola uma responsabilidade importante, na medida em que deverá primeiramente avaliar o comprometimento dos professores com a aprendizagem dos alunos, para então pro- ceder à atribuição de aulas. Também cabe ao Diretor de Escola e Supervisor de Ensino avaliarem os docentes ao final das atividades, considerando os progressos na aprendizagem dos alunos e os resultados de seu trabalho como critério seletivo para os próximos processos de atribuição de aulas de reforço.

Outra determinação presente em toda a legislação que trata das aulas de recuperação e reforço diz respeito à determinação da obrigatoriedade do registro das atividades do professor e desempenho ou avanço dos alunos. Assim, cabe a todo professor do reforço registrar o que efetivamente foi trabalhado e o que logrou resultado com seus alunos. Essa exigência é totalmente condizente com um modelo de avaliação contínua e cumulativa do desempenho do aluno.

O registro dos avanços e dificuldades dos alunos deve ser feito também pelo professor da classe regular, o qual, além de diagnosticar as dificuldades dos alunos, deve ainda informar ao professor do reforço as medidas pedagógicas que já foram tomadas, Tais informações são essenciais para nortear o trabalho do professor do reforço, trabalho esse que, além de diversificado, deve ser fundado nas dificuldades específicas de cada aluno. Não se pode olvidar que a legislação atenta também para o fato de que as ações de recuperação e reforço não eximem o trabalho do docente da classe de recuperação contínua dos alunos. Assim, parale- 
lamente ao trabalho do reforço, o professor da classe regular deve promover uma ação pedagógica que seja a mais individualizada possível e promover a contínua recuperação de seus alunos.

A Resolução SE 34/2000 alerta para a necessidade de um planejamento cuidadoso por parte da escola, para atender aos alunos com dificuldades de aprendizagem. Também enfatiza o papel indispensável do professor coordenador pedagógico nessa tarefa, pois é ele quem garantirá um vínculo de compromisso entre os professores com relação à aprendizagem do aluno. Assim, prioritariamente nos TPCs e também nas reuniões de conselho de série/ classe, o professor coordenador pedagógico deverá promover a troca de informações entre os professores sobre as dificuldades dos alunos, propiciando uma constante orientação, acompanhamento e avaliação do processo de recuperação paralela e reforço dos alunos.

Aos docentes das aulas de reforço a legislação determina que desenvolvam um trabalho diversificado e significativo. De fato, o trabalho de recuperação dos alunos deve apresentar-se diverso daquele oferecido pelo professor da classe regular, pois se o aluno não aprendeu com a metodologia do professor regular, não é pedagogicamente correto que se repita o mesmo procedimento pelo professor do reforço. Esse trabalho precisa ser significativo, atraente e motivador; não deve apresentar um caráter punitivo, mas uma nova possibilidade de aprender e agora de forma mais individualizada, para atender à diversidade de características, de necessidades e ritmos de cada aluno.

As aulas devem centrar-se no desenvolvimento de habilidades básicas que auxiliarão a aprendizagem nas diferentes disciplinas escolares. Assim, ao invés de se priorizar o desenvolvimento de conteúdos específicos, a prioridade deve ser o desenvolvimento de habilidades básicas que contribuirão para todas as áreas de conhecimento. As dificuldades específicas com os conteúdos das disciplinas devem ficar a cargo, sobretudo, do trabalho do professor da classe regular, que deve cuidar delas a partir da recuperação contínua dos alunos no desenvolvimento das aulas regulares.

Os projetos de recuperação paralela e reforço deverão ocorrer a partir de decisão do Conselho de Série/Classe, devendo ser propostos com base nas fichas de avaliação diagnóstica, elaboradas pelo professor da classe regular. Deverão ser elaborados em conjunto com os professores, e não somente pela coordenação pedagógica, e aprovados pela Diretoria de Ensino.

Cabe à direção da escola e à coordenação pedagógica coordenar, implementar, acompanhar e avaliar os referidos projetos, disponibilizar espaço físico e material pedagógico, promover a integração com as famílias 
dos alunos, enfim, zelar para que o reforço apresente um impacto positivo na aprendizagem dos alunos. À Supervisão de Ensino e Oficina Pedagógica compete acompanhar e orientar as unidades escolares, capacitar professores de reforço e avaliar a execução dos projetos de reforço e seus resultados, propondo reformulação das ações quando necessário.

A legislação ainda possibilita a formação de unidades pólo - escolas que atenderiam classes com turmas formadas por alunos de diferentes escolas. Essas unidades podem ser constituídas em situações nas quais o número de alunos para as aulas de reforço não é suficiente em uma determinada escola para a formação de classes, quando então seriam reunidos alunos de diferentes escolas para a formação das turmas.

As unidades pólo também podem ser constituídas em situações de facilidade de acesso dos alunos à referida unidade polo. Como exemplo, poderiam ser criadas unidades pólo com turmas de reforço de $1^{\mathrm{a}}$ a $4^{\mathrm{a}}$ séries do bairro, em escolas que atendem a alunos de $5^{\mathrm{a}}$ a $8^{\mathrm{a}}$ séries. Essa determinação também é bastante conveniente para a formação de turmas de alunos da zona rural, pois é sabido que há uma grande dificuldade em garantir as aulas de reforço para esses alunos devido a problemas de transporte escolar.

A Resolução SE 42, de 5/5/2004, que regulamenta os estudos de recuperação e reforço na rede estadual de ensino, ao determinar as atribuições do diretor de escola, do coordenador pedagógico, do professor da classe e da diretoria de ensino e oficina pedagógica, demonstra uma efetiva preocupação com a aprendizagem do aluno. Todos esses agentes da escola devem, a partir da avaliação contínua, tomar as providências e reformular ações sempre que necessário para garantir a aprendizagem contínua durante o ciclo. Se ainda assim o aluno não desenvolver as competências, habilidades e conhecimentos, cabe à escola oferecer-lhe a recuperação de ciclo.

A temática do reforço ainda foi contemplada na Resolução SE 131, de 4/12/2003, que instituiu o projeto Bolsa Mestrado da Secretaria de Estado da Educação de São Paulo. Nela ficou determinado que as bolsistas designadas para atuarem nas Diretorias de Ensino e liberadas da carga horária de até dezesseis horas semanais para dedicar-se ao curso de pós-graduação, atuarão nas Oficinas Pedagógicas ou Núcleos Regionais de Tecnologia Educacional, para exercerem prioritariamente o desenvolvimento e acompanhamento de projetos de recuperação e reforço da aprendizagem nas unidades escolares.

Do exposto, é possível concluir que há um conjunto amplo de determinações legais que, se aplicadas, contribuiriam para garantir e elevar a qualidade de ensino. 
COMO FUNCIONAM OS PROJETOSDE RECUPERAÇÃOEREFORÇOEAPRÁTICADOS PROFESSORES

Analisada a legislação que regulamenta as classes de recuperação e reforço dos alunos, passo a relatar os dados coletados em uma diretoria de ensino do interior paulista, em trabalho por mim realizado na oficina pedagógica, juntamente com outras três mestrandas, enquanto membro da equipe de bolsistas do projeto Bolsa Mestrado do governo do Estado de São Paulo.

Esse trabalho iniciou-se em 2004 e foi pioneiro, visto que o referido grupo de mestrandas foi o primeiro a desempenhar atividades de acompanhamento às aulas de reforço das escolas estaduais. Os dados foram coletados durante o primeiro semestre de 2004, por meio de três visitas em 17 escolas estaduais da cidade de Araraquara.

Na primeira visita foi realizada uma entrevista com o professor coordenador pedagógico da escola, com o objetivo de explicitar o trabalho a ser desenvolvido pela equipe de mestrandas e discutir alguns aspectos tanto da legislação que regulamenta o reforço como dos projetos de reforço das escolas, que já haviam sido analisados pela equipe de mestrandas e homologados pela Diretoria de Ensino. A segunda e a terceira visitas ocorreram nos horários de aulas e nas classes de reforço, sen- do que as mestrandas assistiam às aulas, trocavam idéias com as professoras e preenchiam relatório exigido pela Oficina Pedagógica. O relatório implicava a apresentação de alguns dados como: atividades; ambientes; recursos utilizados; conteúdos, conceitos e metodologia desenvolvidos no dia; número de alunos presentes e algumas informações que eram obtidas com os professores quanto ao registro do desempenho dos alunos.

As três primeiras visitas permitiram uma coleta de dados que, apesar de ainda incipiente, possibilitou identificar alguns problemas que precisavam ser repensados pela escola, pela equipe da oficina pedagógica e poder público, os quais são relatados a seguir.

Foi possível constatar, pelos dados, que a maioria dos professores das aulas de reforço é iniciante. Eles ocupam a posição de professores eventuais na escola (não são professores efetivos) e reclamam da necessidade de capacitações para refletirem sobre o trabalho que desenvolvem.

A metodologia e materiais utilizados nas aulas de reforço, no ensino médio, em geral são os mesmos que os da classe regular. Nesse nível, o reforço é entendido como "plantão de dúvidas", e a freqüência às aulas de reforço é relevante apenas na semana das provas. Também não foi raro encontrar classes funcionando com apenas três alunos ou ainda sem alunos no dia da visita, embora a escola possua uma lista bastante extensa de 
educandos enviados para as aulas de reforço. Há também uma escola do ensino médio que não ofereceu aulas de reforço nesse semestre.

A baixa freqüência às aulas de reforço também ocorre em escolas do segundo ciclo do ensino fundamental. Pelas informações obtidas com professores, coordenadores e direção de escolas, pôde-se perceber que ainda não há a devida valorização das aulas do reforço. A maioria dos alunos considera, inclusive, que com a progressão continuada não há necessidade da freqüência. Isso demonstra a pouca importância que os jovens atribuem ao aprender, fato bastante preocupante se considerarmos o atual momento histórico, em que os conhecimentos são imprescindíveis para a inclusão social.

Não menos preocupante é concluir que a escola não está conseguindo motivar os alunos o necessário para conseguir a adesão e a participação deles em seus projetos e, em conseqüência disso, está produzindo a exclusão escolar, uma vez que só se garante a qualidade de ensino por meio de uma relação pedagógica marcada pelo comprometimento de todos os segmentos da escola, em especial dos professores e alunos.

Nas escolas onde o coordenador pedagógico desenvolve atividades de formação contínua com os professores de reforço, as aulas tornam-se mais diversificadas e interessantes para os alunos. Todavia, vale lembrar que embora a legislação determine que os professores das aulas de reforço devem participar dos HTPCs (Horários de Trabalho Pedagógico Coletivo em que se desenvolve a formação contínua do professor com a presença do professor coordenador pedagógico), apenas uma minoria desses professores participa de tais reuniões, uma vez que eles não recebem remuneração para isso. A freqüência do professor do reforço aos HTPCs ocorre apenas em algumas escolas e nos casos em que o docente é professor de classe regular da escola e, portanto, remunerado para os mencionados horários de trabalho pedagógico.

Em algumas escolas é evidente a preocupação do professor coordenador pedagógico com os projetos de reforço. Em uma atuação certamente produtiva, ele interage continuamente com os professores, promove a reflexão e a troca de idéias entre eles, apresenta-lhes sugestões, acompanha as aulas e fornece os materiais de que eles precisam, entre outras ações condizentes com a função que exerce.

A freqüência dos alunos é boa nas escolas de ciclo I do ensino fundamental, mas decresce nas classes de ciclo II do ensino fundamental e ensino médio.

\section{CONCLUSÕES}

O trabalho ora apresentado permitiu concluir que as aulas de recuperação paralela e reforço da aprendizagem constituem elemento essencial 
para assegurar a qualidade do ensino e não transformar a progressão continuada em mera promoção automática. De fato, é por meio delas que o aluno que apresenta dificuldades de aprendizagem pode se beneficiar, recebendo tratamento diferenciado e individualizado que permita progressão continuada com efetiva aprendizagem.

A pesquisa constituiu, também, motivação bastante para um projeto de doutorado que está sendo desenvolvido pela autora e que objetiva identificar as contribuições dos projetos de recuperação e reforço, bem como os limites e possibilidades de uma escola pública de qualidade organizada em ciclos.

\section{REFERÊNCIAS}

BARRETO, E. S.de S. e MITRULIS, E. Trajetória e desafios dos ciclos escolares no país. Fórum de Debates, Anais 2002, São Paulo, 2002.

BRASIL. Lei de Diretrizes e Bases da Educação Nacional. Brasília, 1996.

GUILHERME, C. C. F. A progressão continuada e a inteligência dos professores. 2002. Tese (Doutorado) -Universidade Estadual Paulista Júlio de Mesquita Filho, Araraquara, 2002.

PARO, V.H. Reprovação escolar: renúncia à educação. São Paulo: Xamã, 2001.

SÃO PAULO (Estado) Secretaria de Educação. Resolução SE $\mathbf{n}^{\circ}$ 49, de marco de 1996. Dispõe sobre estudos de reforço e recuperação paralela na rede estadual de ensino. São Paulo, 1996.

SÃO PAULO (Estado) Secretaria de Educação. Deliberação CEE n 09/97. Institui no Sistema de Ensino do Estado de São Paulo o regime de progressão continuada no ensino fundamental. São Paulo, 1997a.

SÃO PAULO (Estado) Secretaria de Educação. Indicação CEE $\mathbf{n}^{\circ}$ 08/97. Dispõe sobre o regime de progressão continuada. São Paulo, 1997b.

SÃO PAULO (Estado) Secretaria de Educação. Indicação CEE n 22/97. Dispõe sobre avaliação e progressão continuada. São Paulo, 1997c.

SÃO PAULO (Estado) Secretaria de Educação. Parecer CEE $n^{\circ}$ 67/98. Dispõe sobre Normas Regimentais Básicas para as escolas estaduais. São Paulo, 1998a.

SÃO PAULO (Estado) Secretaria de Educação. Resolução $\mathrm{SE} \mathrm{n}^{\circ}$ 67, de abril de 1998. Dispõe sobre estudos de reforço e recuperação paralela na rede estadual de ensino. São Paulo, 1998b.

SÃO PAULO (Estado) Secretaria de Educação. Resolução SE $\mathbf{n}^{\circ}$ 7, de abril de 1999. Dispõe sobre estudos de reforço e recuperação paralela na rede estadual de ensino. São Paulo, 1999.

SÃO PAULO (Estado) Secretaria de Educação. Resolução $\mathrm{SE} \mathrm{n}^{\circ}$ 34, de abril de 2000. Dispõe sobre estudos de reforço e recuperação paralela na rede estadual de ensino. São Paulo, 2000.

SÃO PAULO (Estado) Secretaria de Educação. Resolução $\mathrm{SE} \mathbf{n}^{\circ} \mathbf{4 0}$, de abril de 2001. Dispõe sobre atribuição de aulas de recuperação e reforço na rede estadual de ensino. São Paulo, 2001.

SÃO PAULO (Estado) Secretaria de Educação. Resolução $\mathrm{SE} \mathbf{n}^{\circ} 27$, de abril de 
2002. Dispõe sobre estudos de reforço e recuperação paralela na rede estadual de ensino. São Paulo, 2002.

SÃO PAULO (Estado) Secretaria de Educação. Resolução $\mathrm{SE} \mathbf{n}^{\circ}$ 84, de agosto de 2003. Altera a Resolução SE 27/02 e extingue a recuperação de férias. São Paulo, 2003a.

SÃO PAULO (Estado) Secretaria de Educação. Resolução SE $n^{\circ} 131$, de dezembro de 2003. Dispõe sobre estudos de reforço e recuperação paralela na rede estadual de ensino. São Paulo, 2003b.

SÃO PAULO (Estado) Secretaria de Educação. Resolução $\mathrm{SE} \mathrm{n}^{\circ}$ 42, de maio de 2004. Dispõe sobre estudos de reforço e recuperação paralela na rede estadual de ensino. São Paulo, 2004.

SILVA, J.M.B. Progressão continuada por ciclos, trabalho docente e qualidade do ensino: um estudo de caso em escola de ensino fundamental do interior paulista. 2001. Dissertação (Mestrado) Universidade Estadual Paulista Júlio de Mesquita Filho, Araraquara, 2001.

Encaminhado em: 21/03/05

Aceito em: 25/11/05 